\title{
KONTRIBUSI KAUM WANITA DALAM PENGEMBANGAN SISTEM USAHA TANI MINAPADI DI DESA NANGGERANG, BINONG, KABUPATEN SUBANG
}

\author{
Mohammad Noor ${ }^{*}$ ) dan Khaidir Ahmady Us ${ }^{* *}$
}

\begin{abstract}
ABSTRAK
Suatu survei dilakukan untuk mengetahui kontribusi kaum wanita dalam pengembangan sistem usaha tani minapadi di Desa Nanggerang, Kecamatan Binong, Kabupaten Subang-Jawa Barat.

Metode yang digunakan adalah Zero-One Relationship Approach yaitu membagi responden menjadi 2 kelompok, masing-masing kelompok yang dibina (koperator) dan kelompok yang tidak dibina tetapi dipantau kegiatan usaha taninya (non koperator). Data primer diperoleh melalui wawancara dengan kuisioner terpola. Dari data ini dilakukan analisis tingkat produktivitas antara petani koperator dengan non koperator, yang meliputi produktivitas hasil produksi padi, hasil produksi ikan, pendapatan kotor dan produktivitas hasil bersih per jam tenaga kerja.

Berdasarkan hasil survei yang dilakukan diketahui bahwa wanita memberi kontribusi sebesar 53,23\% (koperator) dan 53,40\% (non koperator) dari jumlah waktu yang diperlukan untuk seluruh aktivitas sistem usaha tani minapadi per tahunnya. Tingkat produktivitas wanita lebih tinggi dari pada pria baik wanita koperator maupun non koperator. Sedangkan tingkat produktivitas wanita tani koperator lebih baik dibanding non koperator.
\end{abstract}

\section{ABSTRACT: Women Contributions in the Development of Fish-rice Farming System in the Village of Nanggerang, Binong, Subang Regency, by: Mobammad Noor and Kbaidir Abmady Us.}

The study had been carried out to reveal the contribution of women in the development of the fish-rice farming systems in Nanggerang village, Binong, Subang, West Java. The method of the survey was zero-one-relationship approach by dividing respondents into two groups, as guided group (cooperator) and non guided group (non cooperator), in which their activities were monitored.

The primary data was collected through interview. Productivity rates between cooperator farmers and non cooperator farmers were analyzed by considering productivities of rice and fish as well as gross and net production per man-hour.

The results showed that women contributed 53,23\% (cooperator) and 53,40\% (non cooperator) of the total person-hour needed in rice-cum-fish. The productivity of women was higher than that of men, regardless of coperator or non cooperator farmers. The productivity of women cooperator was better than that of the non cooperator.

KEYWORDS: Women contribution, fisb-rice farming system.

") Peneliti pada Instalasi Penelitian Perikanan Laut Slipi, Jakarta

*n) Peneliti pada Balai Pengkajian Teknologi Pertanian Sukarami 


\section{PENDAHULUAN}

Kebijaksanaan Pelita VI bidang pertanian adalah peningkatan pendapatan dan taraf hidup petani dan nelayan, memperluas lapangan kerja dan kesempatan usaha serta mengisi dan memperluas pasar. Untuk mencapai tujuan usahausaha pokok pembangunan pertanian meliputi: (a) pengembangan diversifikasi dan intensifikasi pertanian, (b) peningkatan rehabilitasi sumber daya pertanian dan (c) pengembangan demokrasi ekonomi di sektor pertanian.

Sistem usaha tani minapadi merupakan salah satu usaha pengembangan diversifikasi pertanian yang diarahkan untuk mencapai tujuan pembangunan pertanian Pelita VI.

Peran wanita di pedesaan tidaklah dapat diabaikan. Wanita tani di pedesaan mengemban tugas ganda. Di samping tugas, tanggung jawab utama dan perannya dalam membina keluarga sehat sejahtera, terutama dalam pembinaan dan memberi motivasi pada generasi (remaja) yang sehat dalam rangka pembangunan manusia seutuhnya (Suwondo, 1990), mereka juga ikut terlibat dalam sistem usaha tani guna meningkatkan pendapatan dan kesejahteraan keluarga.

Pengabaian terhadap wanita di dalam perencanaan pembangunan pertanian akan menyebabkan dampak-dampak penurunan yang serius seperti terhadap penurunan produksi pangan, penurunan pendapatan dan penurunan kesejahteraan petani (Michelwait et al., 1976; Dixon-Muller and Anker, 1988; Obbo, 1985).

Hasil penelitian Oka et al. (1992) pada sistem usaha tani minapadi di Desa Nanggerang, Kecamatan Binong, Kabupaten Subang, Jawa Barat menunjukkan bahwa rata-rata wanita bekerja $910 \mathrm{jam} / \mathrm{ha} / \mathrm{tahun}$ untuk kelompok tani binaan (koperator), bagi kelompok tani tidak dibina tetapi dipantau kegiatan sistem usaha taninya (non koperator) $905 \mathrm{jam} / \mathrm{ha} /$ tahun pada tahun 1989/1990 dengan nilai uang masing-masing sebesar Rp 273.133,- (koperator), Rp 271.563,- (non koperator).

Gambaran mengenai sampai seberapa besar kontribusi wanita dalam pembangunan pertanian belumlah begitu jelas. Sebab wanita yang bekerja di bidang pertanian biasanya hanya dipandang sebagai tenaga keluarga. Untuk itulah penelitian ini dilakukan.

Penelitian bertujuan untuk memperoleh informasi dan gambaran mengenai peran dan kontribusi wanita dalam pengembangan sistem usaha tani minapadi di Desa Nanggerang, Kecamatan Binong, Kabupaten Subang, Jawa Barat. 


\section{BAHAN DAN METODE}

Penelitian ini dilakukan dengan menggunakan metode survei. Penarikan contoh dilakukan secara acak sederhana di mana jumlah petani responden yang dipilih sebanyak 22 orang petani binaan (koperator) dan 22 orang petani non koperator (tidak dibina).

Data primer diperoleh melalui wawancara yang didasarkan pada kuesioner terpola. Dengan pendekatan Zero-One Relationsbip Approach, yaitu membagi responden berdasarkan petani binaan (koperator) dan petani tidak dibina (non koperator). Pembagian ini bertujuan untuk mengetahui sampai sejauh mana petani yang telah dibina oleh Puslitbang Tanaman Pangan pada tahun 1987-1989 mampu meningkatkan kesejahteraannya. Pembinaan dimaksudkan untuk meningkatkan produksi padi di desa lahan irigasi dan tadah hujan melalui perubahan dari sistem usaha tani minapadi secara tradisional ke sistem produksi yang intensif (pembaharuan teknologi produksi padi yang baru disesuaikan dengan kecocokan lahan). Sistem usaha tani dilakukan mengikuti strategi pembangunan pertanian yang beralih dari pendekatan satu komoditas menjadi pendekatan diversifikasi multi komoditas pertanian untuk menopang kecukupan dan peningkatan kesejahteraan petani.

Metode analisis untuk mengemukakan kontribusi wanita dalam pengembangan sistem usaha tani minapadi adalah dengan tabulasi dan diuraikan secara diskriptif, serta analisis tingkat produktivitas kerja wanita.

\section{HASIL DAN PEMBAHASAN}

\section{Karakteristik Wilayah}

Desa Nanggerang, Kecamatan Binong, Kabupaten Subang, Jawa Barat memiliki luas areal sekitar 414,558 ha dengan rincian dilihat dari komposisi penggunaan adalah sebagai berikut, sawah teknis 292,340 ha; sawah setengah teknis 17,930 ha; tanah darat 98,248 ha dan kolam atau empang 6,00 ha. Rata-rata curah hujan adalah $1380 \mathrm{~mm} /$ tahun dengan jenis tanah aluvial. Untuk sawah teknis maupun setengah teknis hanya dikelola oleh 785 orang petani pemilik dan 544 orang petani penggarap. Sawah teknis mendapat pengairan sepanjang musim dari dam Cimacan-Jatiluhur yang memiliki prasarana pengairan seperti saluran primer 9 buah, sekunder 9 buah, tersier 15 buah dan saluran kuarter 49 buah dengan pintu pembagi air sebanyak 32 buah. Selain itu, prasarana lain bagi menunjang kegiatan petani setempat juga terdapat 2 buah kios sarana produksi, satu kelompok P3A Mitra Cai, satu kelompok petani minapadi dan 4 buah saung pertemuan kelompok. Untuk lebih jelasnya dapat dilihat pada Table 1. Selain itu prasarana jalan yang memperlancar arus pengangkutan hasil bumi dari desa ini cukup memadai untuk menunjang usaha peningkatan pendapatan petani. 
Noor, M. dan Abmady, K.Us.

Table 1. Land use, status of land property and infrastructure in Nanggerang village

\begin{tabular}{llc}
\hline \multicolumn{1}{c}{ Items } & Total \\
\hline $1 \quad$ Land & $292,340 \mathrm{ba}$ \\
& Irrigated Land & $17,930 \mathrm{ba}$ \\
& Semi Irrigated Land & $98,248 \mathrm{ba}$ \\
Dry Land & $6,000 \mathrm{ba}$ \\
& Pond & \\
2 & Farmer & 785 \\
& Farmer Owner & 544 \\
& Farmer Labor & \\
3 & Infrastructure & 9 \\
& Primary Canal & 9 \\
& Secondary Canal & 25 \\
& Tertiary Canal & 49 \\
& Quartiary Canal & 32 \\
& Dividing Inlet/Outlet & \\
4 & Agriculture inputs & \\
& Production facility store & 2 \\
Village Irigation Organization & 1 \\
Group Meeting Hut & 4 \\
Tractor &
\end{tabular}

Source: Anonim. (1992)

\section{Komposisi Penduduk}

Data komposisi penduduk desa Nanggerang pada tahun 1992 menunjukkan jumlah laki-laki dewasa 957 orang, wanita dewasa 1.035 orang, anak laki-laki 483 orang dan anak perempuan 493 orang. Jumlah keseluruhan penduduk 2.968 orang. Dari komposisi penduduk ini jelas terlihat jumlah wanita dewasa lebih banyak dari pada pria dewasa. Hal ini berarti untuk mengelola lahan pertanian kontribusi wanita sangat diperlukan.

\section{Kontribusi Wanita Dalam Pengembangan Sistem Usaha Tani Minapadi}

Kontribusi wanita bagi memenuhi kebutuhan tenaga kerja dalam pengembangan sistem usaha tani minapadi di desa Nanggerang antara petani koperator dan non koperator disajikan pada Table 2 dan Table 3. 
Table 2. Allocation of labor in agriculture activities for cooperator farmers, 1992/1993

\begin{tabular}{|c|c|c|c|c|c|c|c|c|}
\hline \multirow[t]{2}{*}{ Activities } & \multicolumn{4}{|c|}{$R_{\text {ming }}$ season } & \multicolumn{4}{|c|}{ Dry secson } \\
\hline & $\begin{array}{c}\text { Men } \\
\text { bour/ba }\end{array}$ & $\begin{array}{l}\text { Women } \\
\text { bour/ba }\end{array}$ & $\begin{array}{l}\text { Trader } \\
\text { Rp/ba }\end{array}$ & Total & $\stackrel{\text { Man }}{\text { bowr/ba }}$ & $\begin{array}{l}\text { Women } \\
\text { bour/ba }\end{array}$ & $\begin{array}{l}\text { Trader } \\
\text { Rp/ba }\end{array}$ & Total \\
\hline Land Preparation & 250 & - & 70000 & 250 & 241 & $\cdot$ & 70000 & 241 \\
\hline Seedling & 35 & - & - & 35 & 29 & - & - & 29 \\
\hline Irigating & 66 & • & - & 66 & 55 & • & - & 55 \\
\hline Rice Planting & 6 & 168 & - & 174 & 6 & 160 & - & 166 \\
\hline Fish Stocking & 40 & - & - & 40 & 71 & • & . & 71 \\
\hline Fertilizing & 24 & - & - & 24 & 20 & - & - & 20 \\
\hline Weeding & - & 60 & - & 60 & - & 52 & - & 51 \\
\hline Fish Harvesting & 5 & 35 & - & 40 & 5 & 35 & - & 40 \\
\hline Spraying & 20 & - & . & 20 & 18 & - & - & 18 \\
\hline Rice Harvesting & - & 268 & - & 268 & - & 225 & - & 225 \\
\hline Post Harvesting & 1 & 4 & - & 5 & 5 & 15 & - & 20 \\
\hline Total Hours/ba & 447 & 535 & - & 982 & 450 & 486 & - & 936 \\
\hline $\begin{array}{l}\text { Labor Costs } \\
R p / b a\end{array}$ & 260750 & 178335 & 70000 & 439085 & 262500 & 162000 & 70000 & 424500 \\
\hline
\end{tabular}

Table 2. Allocation of labor in agriculture activities for cooperator farmers, 1992/1993

\begin{tabular}{|c|c|c|c|c|c|c|c|c|}
\hline \multirow[t]{2}{*}{ Activities } & \multicolumn{4}{|c|}{ Reing season } & \multicolumn{4}{|c|}{$D_{r y}$ season } \\
\hline & $\begin{array}{c}\text { Man } \\
\text { bour/ba }\end{array}$ & $\begin{array}{l}\text { Women } \\
\text { bowr/ba }\end{array}$ & $\begin{array}{l}\text { Trader } \\
\text { Rp/ba }\end{array}$ & Tocal & $\underset{\text { bour/ba }}{\text { Mas }}$ & $\begin{array}{l}\text { Women } \\
\text { bour/bae }\end{array}$ & $\begin{array}{l}\text { Trader } \\
\text { Rp/Da }\end{array}$ & Tocel \\
\hline Land Preparation & 279 & - & 70000 & 279 & 261 & $\cdot$ & 70000 & 261 \\
\hline Seedling & 33 & - & - & 33 & 24 & - & $\cdot$ & 24 \\
\hline Irigating & 20 & - & $\cdot$ & 20 & 16 & - & $\cdot$ & 16 \\
\hline Rice Planting & 5 & 165 & - & 170 & 5 & 154 & - & 159 \\
\hline Fish Stocking & 20 & $\cdot$ & - & 20 & 45 & $\cdot$ & - & 45 \\
\hline Fertilizing & 25 & $\cdot$ & - & 25 & 21 & $\cdot$ & - & 21 \\
\hline Weeding & - & 50 & - & 50 & $*$ & 43 & $\cdot$ & 43 \\
\hline Fish Harvesting & 4 & 32 & - & 36 & 4 & 26 & - & 30 \\
\hline Spraying & 16 & - & $\cdot$ & 16 & 12 & - & - & 12 \\
\hline Rice Harvesting & - & 253 & - & 253 & - & 180 & - & 180 \\
\hline Post Harvesting & 1 & 2 & $\cdot$ & 3 & 4 & 6 & $\cdot$ & 10 \\
\hline Total Hours/ba & 403 & 502 & $\cdot$ & 905 & 392 & 409 & - & 801 \\
\hline $\begin{array}{l}\text { Labor Costs } \\
\text { Rp/ba }\end{array}$ & 235085 & 167335 & 70000 & 402420 & 228670 & 136335 & 70000 & $\overline{365005}$ \\
\hline
\end{tabular}


Dari Table 2 dan Table 3 ini terlihat bahwa tenaga kerja wanita dominan dalam kegiatan pengusahaan padi, seperti menanam, menyiang, panen ikan, panen padi dan pasca panen. Sedang tenaga kerja pria diperuntukkan pada pengolahan lahan, menyemai, mengairi, menebar benih ikan, memupuk dan menyemprot. Tetapi secara keseluruhan kontribusi tenaga kerja wanita dalam sistem usaha tani minapadi baik petani koperator maupun non koperator lebih besar dibanding pria, yaitu $53,23 \%$ dari seluruh aktivitas sistem usaha tani dilakukan oleh wanita untuk petani koperator dan $53,40 \%$ bagi petani non koperator.

Walaupun dari kedua tabel tersebut juga terlihat bahwa kontribusi wanita petani koperator agak lebih kecil dari pada wanita petani non koperator, tetapi penggunaan jam kerja untuk seluruh aktivitas usaha tani petani koperator lebih besar dari non koperator. Hal ini dapat dimengerti karena petani koperator langsung memperoleh informasi, bimbingan teknologi sistem usaha tani dari peneliti dan aparat terkait lainnya, sedangkan petani non koperator tidak langsung memperolehnya walaupun kegiatan sistem usaha tani mereka tetap dipantau oleh para peneliti yang terlibat serta aparat terkait lainnya.

Dari segi upah hasil kerja ternyata walaupun wanita lebih banyak jam kerja yang digunakannya untuk aktivitas sistem usaha tani minapadi, baik petani koperator maupun non koperator tetapi upah kerja yang mereka peroleh lebih kecil dari pada pria yaitu $R$ p 333,33/jam untuk wanita dan Rp 583,33/jam untuk pria. Rendahnya sistem pengupahan terhadap wanita tani ini mungkin disebabkan oleh latar belakang sosial budaya yang menyebabkan adanya pandangan dalam masyarakat bahwa wanita adalah makhluk yang lemah dan karenanya ruang geraknya hanya terbatas pada lingkungan keluarga dan masyarakat sekitarnya. Selain itu juga masih terdapatnya pandangan bahwa pencari nafkah utama adalah pria sebagai kepala keluarga dan apabila wanita memperoleh pendapatan hal ini hanya merupakan pendapatan tambahan bukan pendapatan utama bagi keluarga (Suwondo, 1990). Pandangan ini tidaklah benar seluruhnya, sebab dalam derap laju pembangunan yang telah dan sedang dilaksanakan oleh pemerintah yang begitu cepat serta pola kehidupan yang semakin komplek dan jarak antar ruang dan waktu yang semakin sempit, kedudukan antara pria dan wanita dalam sebuah keluarga bukanlah hubungan subordinansi atau vertikal, akan tetapi adalah hubungan mitra kerja sama yang mempunyai kedudukan dan fungsi yang sama sesuai dengan tugas masingmasing.

Analisis pendapatan petani koperator dan non koperator dapat dilihat pada Table 4.

Berdasarkan pendapatan petani ini dilakukan analisis tingkat produktivitas yang hasilnya disajikan dalam Table 5. 
Table 4. Analysis of income of cooperator and non cooperator farmers, 1992/1993 (Rp/crop season)

\begin{tabular}{lrc}
\hline \multicolumn{1}{c}{ Component } & Cooperator & Non Cooperator \\
\hline Rice Outputs & $2,634,722$ & $2,635,505$ \\
Fisb Outputs & $2,884,612$ & $1,481,518$ \\
Gross Revenue & $5,519,334$ & $4,135,023$ \\
Production Costs & 913,492 & 517,482 \\
Cost of Labor & $1,003,585$ & 907,425 \\
Total Cost & $1,935,077$ & $1,424,907$ \\
Net Income & $3,584,257$ & $2,710,116$ \\
\hline
\end{tabular}

Table 5. Analysis of productivity rate of cooperator and non cooperator farmers in $1992 / 1993$ (Rp/crop season)

\begin{tabular}{lcccc}
\hline \multirow{2}{*}{ Productivity } & \multicolumn{2}{c}{ Coopeartor } & \multicolumn{2}{c}{ Non Cooperator } \\
\cline { 2 - 5 } & Men & Women & Men & Women \\
\hline Rice Production per Labor-bour & 1.22 & 1.40 & 1.36 & 1.40 \\
Fish Production per Labor-bour & 1.34 & 1.53 & 0.75 & 1.53 \\
Gross Income per Labor-bour & 2.57 & 2.93 & 2.12 & 2.93 \\
Net Income per Labor-bour & 1.67 & 1.90 & 1.39 & 1.90 \\
\hline
\end{tabular}

Berdasarkan Table 5, tampak jelas bahwa dari berbagai parameter produktivitas ternyata tingkat produktivitas tertinggi diperoleh oleh pekerja wanita baik petani koperator maupun non koperator. Hal ini membuktikan lagi anggapan bahwa wanita itu kaum yang lemah tidaklah benar secara keseluruhan. Wanita mampu menghasilkan produktivitas yang baik pada bidangbidang tertentu. Nyatalah kontribusi wanita pada pengembangan sistem usaha tani minapadi di desa Nanggerang cukup besar.

Selanjutnya diketahui pula bahwa produktivitas antara wanita tani koperator dengan non koperator sama baiknya, walaupun kontribusi tenaga wanita koperator sedikit lebih rendah $(53,23 \%)$ dibanding wanita tani non koperator $(53,40 \%)$ dalam seluruh aktivitas usaha tani minapadi. Ravianto (1986) mengemukakan bahwa tingkat produktivitas suatu sistem produksi juga sangat dipengaruhi oleh faktor-faktor yang tidak dapat diukur (invisible input) yaitu berupa kekuatan motivasi (motivation power), pengetahuan (knowledge), teknologi dan organisasi. 
Kekuatan motivasi yang tinggi pada wanita tani koperator inilah yang telah menyebabkan tingginya hasil produktivitas yang mereka capai, walaupun kontribusi mereka pada seluruh aktivitas sistem usaha tani lebih kecil dibanding wanita tani non koperator. Keynes (1936) dalam Ravianto, 1986 mengemukakan bahwa kemakmuran ekonomi banyak bergantung dari adanya driving spirit, sedangkan pertumbuhan ekonomi adalah hasil langsung dari tenaga kerja (Lewis, 1962 dalam Ravianto, 1986).

Berdasarkan hasil penelitian pengembangan sistem usaha tani minapadi yang telah dilakukan pada tahun 1987-1989 juga dilakukan analisis tingkat produktivitas untuk melihat perkembangan dari tahun ke tahun mengenai dampak penelitian pengembangan sistem usaha minapadi (Table 6).

Table 6. Analysis of the productivity rates of cooperator and non cooperator farmers in 1989/1990 and 1990/1991 (Rp/crop season)

\begin{tabular}{|c|c|c|c|c|c|c|c|c|}
\hline \multirow{3}{*}{ Productivity } & \multicolumn{4}{|c|}{ Coopeartor } & \multicolumn{4}{|c|}{ Non Cooperator } \\
\hline & \multicolumn{2}{|c|}{ Men } & \multicolumn{2}{|c|}{ Women } & \multicolumn{2}{|c|}{ Men } & \multicolumn{2}{|c|}{ Women } \\
\hline & \multicolumn{8}{|c|}{$89 / 9090 / 9189 / 9090 / 9189 / 9090 / 9189 / 9090 / 91$} \\
\hline Rice Production per Labor-bour & 1.73 & 1.14 & 1.27 & 0.85 & 1.57 & 1.23 & 1.28 & 1.04 \\
\hline Fisb Production per Labor-bour & 0.20 & 0.32 & 0.15 & 0.24 & 0.14 & 0.15 & 0.12 & 0.14 \\
\hline Gross Income per Labor-bour & 1.94 & 1.46 & 1.42 & 1.10 & 1.72 & 1.33 & 1.39 & 1.18 \\
\hline Net Income per Labor-bour & 1.14 & 0.60 & 0.84 & 0.46 & 1.02 & 0.55 & 0.82 & 0.48 \\
\hline
\end{tabular}

Source: Oka et al. (1992)

Dari Table 6 terlihat bahwa pada tahun 1989/1990 dan tahun 1990/1991 produktivitas wanita lebih rendah dari pada produktivitas pria. Kemudian sejalan dengan perputaran waktu maka pengalaman dan pengetahuan mengenai teknologi produksi sistem usaha tani minapadi bertambah, sehingga pada tahun 1992/1993 tingkat produktivitas wanita meningkat melebihi tingkat produktivitas pria, baik wanita tani koperator maupun non koperator. Dari perkembangan di atas terlihat adanya fenomena yang menarik, tampaknya wanita lebih mudah dalam menerima pembaharuan dan perubahan dibanding dengan pria. Hal ini dapat dimengerti karena wanitalah pada umumnya yang menjadi pengelola keuangan sepenuhnya dalam sebuah keluarga. Sehingga umumnya kaum wanita bila bekerja selalu dilandasi oleh pertimbangan ekonomis. Dengan demikian dapat dikatakan bahwa motivasi ekonomi ini yang menjadi driving spirit wanita tani untuk meningkatkan produktivitasnya melalui keterbukaan dan keluwesan mereka dalam menerima perubahan dan pembaharuan suatu sistem usaha tani. 


\section{KESIMPULAN DAN SARAN}

\section{Kesimpulan}

1. Kontribusi wanita dalam pengembangan sistem usaha tani minapadi di Desa Nanggerang cukup besar yaitu $53,23 \%$ untuk wanita tani koperator dan $53,40 \%$ untuk wanita tani non koperator dari jumlah total waktu yang diperlukan dalam seluruh aktivitas usaha tani per tahun.

2. Produktivitas wanita tani koperator dan non koperator sama baiknya, walaupun kontribusi tenaga dalam seluruh aktivitas sistem usaha tani per tahun lebih besar wanita tani non koperator, ini berarti tingkat produktivitas wanita tani koperator sedikit lebih tinggi dari non koperator.

3. Tingkat produktivitas pria lebih rendah dari pada wanita baik koperator maupun non koperator pada tahun 1992/1993, sedang pada tahun $1989 / 1990$ dan tahun 1990/1991 sebaliknya yaitu tingkat produktivitas pria lebih tinggi dari pada wanita. Hal ini disebabkan wanita lebih mudah dalam menerima pembaharuan dan perubahan dibanding dengan pria, dan wanita pada umumnya menjadi pengelola keuangan sepenuhnya dalam sebuah keluarga. Di samping itu, wanita bekerja selalu dilandasi dengan pertimbangan ekonomis.

4. Dari hasil penelitian ini, tampaknya wanita lebih terbuka dan luwes dalam menerima perubahan dan pembaharuan (earlier adapter) bagi peningkatan produktivitas kerjanya.

\section{Saran}

Perlu dilakukan penelitian lebih lanjut guna melihat secara lebih jelas kontribusi wanita tani dalam pengembangan suatu sistem usaha tani.

\section{DAFTAR PUSTAKA}

Anonim. 1992. Data Statistik Kecamatan Binong, Kabupaten Subang. Jawa Barat.

Dixon-Muller, R. and R. Anker. 1988. Assessing women's economic contributions to development. Background Papers for Training in Population, Human Resources and Development Planning, Paper No. 6. International Labour Office, Geneva, Switzerland, 92 p.

Michelwait, D.; M.A. Riegelmen and C. Sweet. 1976. Women in rural development. Westview Press. Boulder, Colorado. 
Noor, M. dan Abmady, K.Us.

Oka, M.A, D.K.S. Swastika dan W. Sudana. 1992. Impact assessment of rice fish farming system in Indonesia, CRIFC, AARD, Bogor, 42p.

Obbo C. 1985. Development women: "Critical Issues" in William Derman and Scott Whiteford, eds., Social Impact Analysis and Development Lanning in Third World. Social Impact Assessment Series, No. 12. Westview Press. Boulder, Colorado, pp. 199-215.

Ravianto, J. 1986. Produktivitas dan pengukuran: Bagaimana mengukur produktivitas. Seri Produktivitas VIII, Lembaga Sarana Informasi Usaha dan Produktivitas, Jakarta, 196 hal.

Suwondo, T.E. 1990. Peningkatan peranan wanita dalam pembangunan (sub) sektor perikanan. Pros. Puslitbangkan/No. 18/1990, Jakarta, hal 205-208. 